\title{
INTRODUCTION
}

\section{Refugee Voices: Exploring the Border Zones between States and State Bureaucracies}

\author{
DAWN CHATTY
}

\section{Introduction}

S ettled people have been forced to move and nomads have been coerced into settling for as long as there has been history. Until the emergence of the Westphalian concept of the nation (where the state corresponded to the nation, groups of people united by language and culture), movement and mobility were largely recognized and accommodated. However, most contemporary academic disciplines as well as public institutions adopt a particular sedentist perspective on the nation-state. It is commonly recognized that people are displaced and move when political states collapse; they return when political security is restored. The liminal "state" outside the defined territory of the nation-state, where the displaced are found, is regarded as a threat to the world order. ${ }^{1}$ Predominant theory has been that people must be tied to territory, and thus the durable policy solutions advanced are frequently about resettlement. Reality does not support either current forced migration theory or humanitarian aid practices, however, and an epistemological change in thinking about forced migrants is urgently required. This means looking beyond the nationstate-the purview of most academic work in this areaand beyond traditional barriers between disciplines, to give cross-disciplinary attention to the self-expressions and experiences of forced migrants. Furthermore, the forced migrant creates a dilemma in how aesthetic expression is displayed, as their forms of expression cannot be squarely identified with one state or another. The dispossessed and displaced are changed by their experiences in the grey zones between states, and their migrations cannot be neatly catalogued as belonging to one state or culture.

The voices of forced migrants, exiles, and refugees are rarely heard in this context, except to reinforce their passivity, vulnerability, and "neediness" as humanitarian aid recipients in an undefined space between nation-states. The articles in this special issue examine and explore the voices and aesthetic expressions of the displaced and dispossessed as a means of understanding the effects of displacement in terms other than those of the nation-state. They set out to recognize and investigate the frequently silenced voices of forced migrants who exhibit adaptability, resilience, longing, and resistance in the grey zones and borderlands between states and state bureaucracies. We hope to move beyond the term resettlement, in the state of origin, the state of current emplacement, or a third nation-state, in which durable solutions to displacement are conventionally cast, and to examine the experience of displaced groups whose social reality conflicts with the sedentist assumptions on which the nation-state is based.

Jacques Maquet long ago suggested that aesthetic expression is what makes us human, ${ }^{2}$ both reflecting and shaping our social selves. However, the complex implications of Maquet's insight have often been overlooked in the study of forced migration, as even those voices of refugees, exiles, and forced migrants that have been sought by aid agencies and scholars often have been used exclusively in terms of passivity and vulnerability. Rarely has scholarship with the displaced explored the aesthetic expression of other experiences and responses to forced migration. These articles seek 
to redress this oversight by examining forms of resilience and resistance among those marginalized by the nationstate as more than social and economic realities

Aesthetics has a strong significance for human social organization: by referencing shared experience, aesthetics defines an ideational community when it is expressed and perceived, as Maquet has argued. ${ }^{3}$ Aesthetic perception and contemplation can thus be political, and aesthetics may possess "relations of correspondence" to other conceptual categories such as kinship and ethnic authenticity. ${ }^{4}$ The relationship between aesthetics and politics has also been addressed by Gell in his discussion of art as a "technology" embodying complex human intentions, ${ }^{5}$ such as the political motivations behind a Yemeni oral poet's performance. ${ }^{6}$ Traditional oral media in the Middle East are an example of Gell's "technology of enchantment," as orality's "enchantment" establishes relations of social power by conferring associations of morality and legitimacy.

Some work among humanitarian aid practitioners and advocates strives to give voice to refugees and forced migrants through storytelling, such as the Hakawati Project for refugees from Syria in Amman, Jordan, in 2014, and through calligraphy, a good example of which is the Silent University project at the Tate Modern Museum in 2014. Participatory photography is also becoming more widely used by aid practitioners as a medium for self-expression of these "silenced" displaced groups of people. But the aesthetic expression of refugees and other forced migrants has largely been silenced by the state-centric humanitarian aid regime.

In March 2014, the Refugee Studies Centre at the University of Oxford held a conference to explore refugee "aesthetic expression." It was the first time that an academic institution focused on the refugees themselves as producers of knowledge rather than as subjects of inquiry. Some of the questions around which the conference was organized included: Under what circumstances do refugees, exiles, and forced migrants leave a nation-state that is collapsing? How do they cope with existence outside the nation-state? How are resilience and resistance to the "bare life" of the refugee and exile expressed across different refugee experiences? What mechanisms and mediums are used to express loss, perseverance, and hope? How do they perceive their futures and manipulate systems outside the nation-state to achieve their goals of dignity, justice, and freedom (i.e., well-being)? How does cultural expression (e.g., aesthetic expression through art, music, literature, and storytelling) contextualize our understanding of refugee experiences? What are common refugee socio-legal and political expressions (e.g., refugees' preferences not to be put in camps [Syria]), or their preferences for durable solutions (e.g., when should repatriation happen for refugees from Burma)? What are the meanings of voice (e.g., the need not only for articulation but also for dialogue/conversation; the difference between having voice and being heard-soliciting refugees' voices is one dimension, but genuinely listening to what those voices say is a much deeper phenomenological process)?

A call for papers resulted with more than 250 submissions, suggesting that a very rich area of interest had been tapped. From these submissions thirty abstracts were selected for development into presentations at the two-day conference. From these excellent presentations, seven were selected for their coherence to form a special issue of the journal Refuge. The authors of these articles span the social sciences and humanities, and each is involved in giving voice to refugees though scholarly publications, print media, and other aesthetic forms of expression.

These articles challenge preconceived notions of passivity and acquiescence of displaced and dispossessed people and communities, by encouraging the articulation of their perspectives and subjectivities. The seven articles in this special issue all have an interest in the aesthetic expressions of the displaced, the dispossessed, and the migrant, both the mobility of the forced migrant and the universal aesthetics of expression. They offer a unique perspective on the rebuilt lives, identities, and expressions of displaced people in their newly defined worlds in the grey zone between nation-states.

Marfleet's article provides an overview of many of the themes outlined above. He addresses two closely related issues: why do dominant discourses marginalize or even exclude refugee experiences, and how can such experiences be "recuperated"? Throughout the modern era, nation-state and state bureaucracies have rendered refugees as "the other." Using examples from Europe, North America, Asia, Africa, and Australasia, he examines the purposes of such exclusion and the implications for refugees in the wider human society. Marfleet considers the relationship between the experience of displacement and the means of reflecting upon it. What does it mean to narrate life-changing experiences? How are they transmitted across generations and by "post-memory"? What distinguishes individual from collective memories? And finally, is it enough to "give voice" to refugees?

Fiske's contends with the cry of detained refugees "We are human, not animals," which is often called out or painted on banners during protests against detention when they seek asylum in Western states. Drawing on material from fieldwork in Australia and linking the struggles of refugees there to global trends toward rejection of universal human rights, Fiske attempts to make sense of the dehumanizing discourses and punitive polices as well as hard-line responses to detainee protests that she witnessed. Using Hannah Arendt's contention that conscience, speech, and action are "essential characteristics of the human condition," 
she regards the actions of refugees as both a response to the dehumanising effects of detention and political exclusion, and an assertion that while a human being may be politically stripped of these "essential characteristics of the human conditions," they are inherent in the human condition and agency always remains with the agent. Refugees, she argues, use their "bare humanity" to reclaim human status and a place in the public world.

Hughes turns a historical eye on the meaning of forced migration and settlement though the voices of displaced people and refugees in Germany after the Second World War. She explores how being expelled from childhood homes and placed in "homes by chance" led to the constant re-evaluation of what home means, materially and symbolically, among those so displaced. She identifies three main phases of narration of home: loss, itinerancy, and settlement. The loss of home was experienced as traumatic, when home was emptied of all its material and symbolic content. The itinerancy phase was marked by deprivation, living in other peoples' homes, and difficult relationships between the expelled and receiving communities. The final period is the making of a new "home," where the physical, emotional, and social process of homemaking are reintegrated. The constant contestation and negotiation of home by those who have been expelled has led to an imagined, idealized, and romanticized notion of the "homeland." These conclusions help to make sense of the widespread and common memory among forced migrants and refugees of the homeland often more mythological than grounded in physical space.

Berhman turns to literature to try to understand the way in which the "place" of the refugee has been transformed over the last half-century. He sees two distinct but interlocking processes: the birth of nations in the post-colonial world and the coming of refugee law. Both historic developments highlight the changing fortunes of the refugee. Berhman argues that the negative perceptions of the refugee today are intimately linked to the romanticization of the forced migrant in an earlier era. He examines three novels that deal with the refugee against the background of the emergence of post-colonial nations: Leon Uris's Exodus (1958), Salman Rushdie's Shame (1983), and Benjamin Zephaniah's Refugee Boy (2001). Behrman argues that is it precisely within the contractions of national liberation and of refugee law that the refugee has been caught. The recovery of the refugee as a valorized subject thus depends as much on eschewing the romantic hero of the past as of resisting the debased construction of the refugee that dominates today.

The final three articles draw on field studies in Africa. McQuaid examines how Congolese refugees remake their worlds in Uganda and how they defy both legal and humanitarian frameworks to fight to give voice to the voiceless. Drawing on fieldwork among Congolese human rights defenders, she examines their narratives and experiences as they navigate multiple forms and perpetrators of violence through social action. McQuaid clearly illustrates how Congolese refugees understand, articulate, and deploy notions of human rights as well as how they are shaped by the realities of life in displacement. Dona and Godin examine how new information and communications technologies promote the expression of diasporic and refugee voices outside the nation-state-in transnational and trans-generational spaces that enable the creation of narratives that are both lived and alive. Using material drawn from research with second-generation Congolese and Rwandan forced migrants, the authors clearly identify the way in which these forced migrants express their voices and agency in virtual space. Deramo examines how the production of refugee stories, opinions, and perspectives counter the bio-power of the state. Using as a case study the KANERE Press, a free press founded and produced by exiled journalists living in Kakuma refugee camp in Kenya, she addresses how story and narrative produce a transgressive public sphere in an environment where human rights are routinely violated and the rights to speech and expression are repressed. Deramo argues that the refugee camp is a technology of power that operates to manage and ultimately to subjugate populations whose fate as displaced persons is determined by the nation-state. As refugees tell their stories of life in the camp, they construct a narrative community that exists beyond the control of the camp administration, thereby constructing a politicized public sphere. The persistence of KANERE demonstrates a manner of continued resistance that operates in direct opposition to the ethic of control embedded in bio-power.

These seven articles address the nature of voice, memory, identity, and aesthetic expression of the forced migrant from a variety of perspectives within the social sciences as well as the humanities. Using historical as well as contemporary field material, the authors grapple with the silencing as well as "othering" of the forced migrant and refugee in the context of the nation-state. They also examine and articulate the numerous measures used by advocates and the dispossessed in the grey area between states to express their aesthetics and resilience. Through words and images, forced migrants in the grey zone between states are sometimes able to counter official humanitarian discourse and at other times to extend their impact beyond such narratives to reiterate their common humanity.

Dawn Chatty is emeritus professor of anthropology and forced migration, University of Oxford. The author may be contacted atdawn.chatty@qeh.ox.ac.uk. 


\section{Notes}

1 James Scott, The Art of Not Being Governed: An Anarchist History of Southeast Asia (New Haven, ст: Yale University Press, 2009).

2 Jacques Maquet, The Aesthetic Experience: An Anthropologist Looks at the Visual Arts (New Haven, ст: Yale University Press, 1986), 8.

3 Ibid.

4 Ibid.

5 Alfred Gell, "The Technology of Enchantment and the Enchantment of Technology," in Anthropology, Art and
Aesthetics, ed. Jeremy Coote and Anthony Shelton, 40-66 (Oxford: Clarendon, 1992). See also Jeremy Coote, "'Marvels of Everyday Vision': The Anthropology of Aesthetics and the Cattle Keeping Nilotes," in Anthropology, Art, and Aesthetics, ed. Jeremy Coote and Anthony Shelton, 245-73 (Oxford: Clarendon, 1992).

6 Steven Caton, Peaks of Yemen I Summon: Poetry as Cultural Practice in a North Yemeni Tribe (Berkeley: University of California Press, 1990). 